\title{
Exploración de las ideas de Winnicott sobre la adolescencia y el conflicto de generaciones
}

\author{
Exploration of Winnicott' ideas regarding \\ adolescence and the conflict \\ of generations
}

Alejandro KLEIN

\begin{abstract}
Resumen
En este trabajo se busca establecer algunas contribuciones de Winnicott em relación al conflicto de generaciones, la adolescencia y la educación. El concepto de conflicto de generaciones es un eje fundamental para pensar la adolescencia y su relación con el mundo adulto. Destacamos especialmente ideas de Winnicott en relación a la educación, con una perspectiva crítica de la perspectiva de adaptación, tema este que está de acuerdo con su concepto de crecimiento, agresión al servicio de la pulsión de vida y el self verdadero.
\end{abstract}

Palabras Ilave: Adolescente; Educación; Relaciones intergeracionales; Teoría Winnicottion.

\begin{abstract}
This paper seeks to establish some contributions of Winnicott related to adolescence, education, and the conflict of generations. The conflict of generations concept is a fundamental axis when considering adolescence and its relationship with the adult world. Winnicott's ideas regarding education are especially emphasized, and therefore, a critique of the proposal of education as adaptation. This theme is consistent with his concept of growth, aggression in the service of the drive for life and true self.
\end{abstract}

Keywords: Adolescent; Education; Intergenerational relations; Winnicottion Theary

Recordemos que Winnicott fue y es un psicoanalista (y pediatra) inglés de enorme influencia. Especialmente se le recuerda y estudia en relación a su concepto de objetos y fenómenos transicionales (Winnicott, 1981). A partir de una revisión atenta de algunas obras de Winnicott se propone un análisis de las ideas del autor sobre la adolescencia y la educación, sugiriendo una comparación entre la educación desde la óptica institucional, la posible educación de los padres y

$\nabla \nabla \nabla$

1 Universidad de Guanajuato, División de Ciencias Sociales y Humanidades, Departamento de Gestion Publica y Desarrollo. Campus León, Blvd. Puente Milenio, 1001, 37670, León, Guanajuato, México. E-mail: <alejandroklein@hotmail.com>. 
la educación desde una perspectiva estructurante de la adolescencia, en cuanto emergente social.

El trabajo se complementa con algunos apuntes en torno a los procesos de confrontación tal como los presenta Winnicott. Estas reflexiones pueden ser consideradas como una perspectiva teórica, clínica y técnica original, alejada de lo que se establece como propio de la "rebeldía" adolescente desde el punto de vista social.

\section{Sociedad y crecimiento}

Cabe señalar que su perspectiva de la sociedad es muy escéptica, especialmente en lo que hace a los logros de la adaptabilidad. Concibe a la misma como dependiente del crecimiento colectivo de los individuos y la cual se reconstruye a cada momento, indicando asimismo que la independencia como producto social es un sentimiento y no una realidad en sí (Winnicott, 1972). Esa reconstrucción permanente de la sociedad tiene el objetivo de garantizar el crecimiento personal y colectivo, y está al servicio del sujeto. Lo sano depende entonces de la lealtad a una zona de la sociedad y esencialmente del proceso de crecimiento:

Se advertirá que la palabra perfecto no entra en esta formulación; la perfección tiene que ver con las máquinas, y las imperfecciones que son características de la adaptación humana a la necesidad constituyen una cualidad esencial del ambiente que facilita (Winnicott, 1972, p.180).

Probablemente para Winnicott no tienen sentido las dicotomías inadaptado-adaptado o dependencia-independencia. Su análisis se centra más bien en los pares madurez-inmadurez, responsabilidad-irresponsabilidad en relación al crecimiento y el paso del tiempo, lo que preserva la libertad para tener ideas y la posibilidad de actuar por impulso y espontaneidad, siempre que los padres sean los que se hagan cargo de la responsabilidad (Winnicott, 1972).

En este sentido su perspectiva se aparta del adaptacionismo: "Debido a que el crecimiento es 170 básicamente imperfecto no implica ninguna adaptación. La adaptación tiene que ver con la perfección, lo que en realidad implica que se genere un pseudocrecimiento y una pseudomadurez" (Winnicott, 1972, p.193), lo que se puede entender como homologable al concepto de falso self (Winnicott, 1981).

Para Winnicott un logro de salud mental se podría tomar como la capacidad de adaptación sin gran pérdida de la espontaneidad. Como se insistirá más adelante, la salud mental se relaciona en Winnicott a la capacidad de madurar y crecer desde un ambiente facilitador no intrusivo. Sugerimos que la perspectiva winnicottiana establece que si la sociedad y la familia hacen adecuadamente las cosas (y eso es proporcionar un ambiente facilitador no intrusivo), se establecen las condiciones que permiten la expresión del crecimiento como una continuidad que el self establece desde sí mismo: "gracias a esa continuidad, y sólo con ella, puede el nuevo bebé, en situación de dependencia, gozar de continuidad en la línea de su vida, y no pasar por una pauta de reacción ante lo impredecible y volver a empezar una y otra vez" (Winnicott, 1972, p.183).

El modelo que Winnicott desarrolla sobre la adolescencia es sumamente original y se diferencia de otras propuestas psicoanalíticas (Dolto, 1990; Erikson, 1991, 2009; Freud, 1905; Freud, 1985; Kancyper, 1992). Se podría indicar que para Winnicott en el caso del adolescente no hay nada que lograr especialmente, sólo crecer. El crecimiento es lo prioritario, todo se subordina a él. Con respecto a la independencia señala que aunque ésta nunca llega a ser absoluta, el individuo en su madurez: "...puede sentirse libre e independiente, tanto como haga falta para la felicidad y para el sentimiento de posesión de una identidad personal" (Winnicott, 1972, p.180). Pero esta situación es especialmente compleja en el momento de la adolescencia, pues, a pesar de lo válido de las ideas de Winnicott, no se puede ignorar que la misma pasa por varios requisitos institucionales y sociales que implican negociación y grados de "adaptabilidad" (Erikson, 2009; Klein, 2004; Maier, 1980), lo que se podría relacionar al concepto de falso self en cuanto necesidad de adaptación social (Winnicott, 1981). 


\section{Familia y crecimiento}

Al plantear desde qué ángulos se moldea su actitud psicoterapéutica en relación al adolescente, Winnicott destaca el papel especial de la familia en facilitar la inmadurez del adolescente y el logro gradual de su madurez, sin pérdida de su espontaneidad (Winnicott, 1972). Desde esta perspectiva la familia no está ahí para que el adolescente se adapte a ella, sino que es ella la que se debe adaptar al adolescente para contener el crecimiento adolescente. Y si la familia no puede ser usada para tal fin, se hace necesario unidades sociales que lo puedan hacer (Winnicott, 1972).

Pero, si por el contrario, la familia se ubica en una actitud educadora, existe el riesgo de que algo espere a cambio, además del agradecimiento (Winnicott, 1972, 1984). Se podría pensar entonces que si el adolescente no agradece, no es porque sea desagradecido sino porque el crecimiento genera agresividad. En este punto, como en otros, las ideas de Winnicott son extremadamente cuidadosas y sutiles. El autor reivindica especialmente el derecho del niño en criticar a sus padres, pero señala explícitamente que existe un sentimiento de "gratitud" del hijo frente a los padres que lo han cuidado, pues éstos aseguran "un marco dentro del que cada niño puede gradualmente encontrarse a sí mismo y al mundo, y establecer una relación activa entre ambos" (Winnicott, 1994, p.104). En tal sentido la gratitud será expresión de madurez emocional, y el autor indica la necesidad de su presencia como una manifestación de la integración psicosoma y mundo. Winnicott es más preciso aún, e indica que gratitud y reconocimiento no son similares: "Permítaseme destacar una vez más que el resultado de tal reconocimiento no será gratitud, y ni siquiera alabanza; el resultado será una disminución del temor" (Winnicott, 1994, p.105). Disminución, que como ya se indicó, se puede asociar también a madurez emocional en cuanto disminuye el temor a la dependencia del objeto (Winnicott, 1994).

Al mismo tiempo, el autor parece indicar que otra expresión de madurez emocional, aunque desde los padres mismos, es que estos no reclamen o esperen tal gratitud, ya que: "antes que gratitud prefieren ver a sus hijos crecer y convertirse, a su vez, en padres y constructores de hogares" (Winnicott, 1994, p.104).

Es necesario indicar que esta postura de Winnicott, de destacar la necesidad de crítica a los padres (crítica que se ha de integrar junto al reconocimiento y la gratitud), se deriva de su concepción del propio proceso de crecimiento, como una especie de vitalidad asociada al hecho de estar vivo consolidando el self genuino. No se trata de una agresividad reactiva (Kohut, 1977) de efecto secundario, sino de la propia afirmación del ser como un objetivo en sí mismo, en cuanto implica la afirmación del self.

De esta manera no es una agresividad que se explica por un objeto externo a ser destruido, sino que es más bien una condición intrínseca al crecimiento: "En la fantasía inconsciente, el crecimiento es intrínsecamente un acto agresivo" (Winnicott, 1972, p.185) inseparable de un ambiente facilitador suficientemente bueno que no interfiera con esta maduración progresiva (Winnicott, 1972).

En el caso de la adolescencia, esta agresividad intrínseca al servicio del crecimiento pasa a tener características peculiares y con sus propias manifestaciones: "Si en la fantasía del primer crecimiento hay un contenido de muerte, en la adolescencia el contenido será de asesinato" (Winnicott, 1972, p.186). Creemos que uno de los aspectos en los que Winnicott trabaja la agresividad adolescente al servicio del crecimiento es la confrontación. La confrontación parece ser algo más intenso que un diálogo fuerte: esta sería una contraposición de posiciones, pues contiene algo del choque, algo de lo agresivo en juego (Klein, 2003), aunque sin llegar a la violencia como filicidio o parricidio (Winnicott, 1972)

Quizás se podría suponer que la fantasía de asesinato permanece como tal, evitando este asesinato en lo real (Klein, 2006a). Y la forma de que la fantasía no pase al acto es justamente a través de la confrontación, pues la misma implica la preservación de la irresponsabilidad e inmadurez del adolescente, así como implica la madurez, sobrevivencia y responsabilidad del adulto, lo que 
parece consolidar entre ambos una especie de balance que hace que la fantasía de asesinato se resuelva lúdicamente:

Si se quiere que el niño llegue a adulto, ese paso se logrará por sobre el cadáver de un adulto. (Doy por sentado que el lector sabe que me refiero a la fantasía inconsciente, al material que subyace en los juegos)... En algunos casos se podría decir: "Sembraste un bebé y recogiste una bomba". En rigor esto siempre es así, pero no siempre lo parece (Winnicott, 1972, p.186).

\section{Inmadurez y parentalidad}

Otro factor a tener en cuenta es que, salvando situaciones forzadas donde el adolescente debe asumir tempranamente responsabilidades de dinero o del cuidado de otros, la inmadurez e irresponsabilidad adolescente se debe preservar. No hacerlo implica situaciones de grave preocupación:

Pero las cosas son muy distintas cuando, por política deliberada, los adultos delegan la responsabilidad; por cierto que hacer tal cosas puede ser una forma de traicionar a los hijos en un momento crítico. En términos del juego, o del juego de la vida, se abdica en el preciso momento en que ellos vienen a matarlo a uno... el adolescente que triunfa demasiado temprano resulta presa de su propia trampa, tiene que convertirse en dictador y esperar a ser muerto, no por una nueva generación de sus propios hijos, sino por sus hermanos (Winnicott, 1972, p. 188).

A diferencia de la concepción freudiana del padre totémico que no está ni vivo ni muerto (Freud, 1913), o el padre lacaniano (Dör, 1990) que está definitivamente muerto para establecer el orden simbólico, el adolescente necesita un padre responsable, vivo, que no sucumba ni abdique, que se resigne a recibir solamente algún tipo de recompensa y no se ponga celoso por el crecimiento adolescente. Es decir, se trata de un conflicto 172 padres-hijos con un padre que sobrevive, y está bien vivo, a pesar de la confrontación: "los esfuerzos adolescentes que hoy se hacen sentir ... deben ser encarados, convertidos en realidad por medio de un acto de confrontación" (Winnicott, 1972, p.190). Para ello, podría pensarse que el adulto debe ser adulto, y básicamente adulto es aquel que sobrevive al ataque adolescente.

En la teoría winnicottiana, sólo el padre vivo no abdicante de su condición de tal hace efecto de estructura y es el que puede preservar esa irresponsabilidad necesaria para que el adolescente crezca. Es por eso que Winnicott señala enfáticamente la necesidad de que el adolescente viva su inmadurez, preservando su irresponsabilidad (Winnicott, 1972).

\section{Perspectivas de la confrontacion generacional}

Como ya se indicó, la confrontación en Winnicott implica algo de la violencia en juego, violencia atenuada por la inexistencia de represalia o venganza. Tiene su propia fuerza, y esa fuerza es la posibilidad del intercambio y la discusión: "La confrontación se refiere a una contención que no posea características de represalia ni de venganza, pero que tenga su propia fuerza" (Winnicott, 1972, p.193). La violencia se articula a una perspectiva libidinal ya que, como varios autores señalan, Winnicott no acepta en su marco teórico o clínico la pulsión de muerte (N. Bleichmar \& Bleichmar, 1999), probablemente entre otras cosas, porque lo libidinal se articula claramente a su noción de integración psicosomática, lo que se desarrollará enseguida. Por otro lado, un objeto que no es vengador ni retaliativo es además aquel que sobrevive a esta agresividad, lo que a su vez posibilita el uso del objeto y consolida la sensación de confianza (Winnicott, 1972).

Se podría sugerir que Winnicott desarrolla diferentes perspectivas sobre la confrontación y eso explicaría algunas de las complejidades para comprender su pertinencia dentro de la adolescencia. Una de ellas pone el acento en el rol del adulto, en la necesidad de que éste no abdique, de que se muestre vivo y sobreviva, neutralizando 
las fantasías de parricidio y/o filicidio. Es un "ser" adulto. Otra perspectiva es el "hacer" como adulto, el adulto actuando como tal generando las condiciones para que la fantasía agresiva permanezca como tal, no incentivando la madurez prematura del adolescente. Winnicott quizás es optimista en que entre el "ser" y el "hacer" del adulto haya complementación, aunque se podría indicar que este par depende a su vez de condiciones sociales que hacen a la legitimización del "adulto" en la sociedad (Klein, 2006a). Por tanto, la problemática de la confrontación es altamente compleja- y escapa a su reducción a un conflicto entre deseo y fantasía, tal como se instaura desde la neurosis (Laplanche \& Pontalis, 1981).

Cabe preguntarse si el modelo de confrontación que desarrolla Winnicott es entonces exactamente asimilable a la confrontación tal como se entiende socialmente (Klein, 2002), en tanto "rebeldía" tolerada por la sociedad. Por un ladoes probable que así sea, en cuanto señala una relación entre confrontación, rebelión y libertad como forma de negociación con el mundo adulto (Winnicott, 1972); por otro lado sin embargo, da la impresión de que el concepto winnicottiano es más original ya que la confrontación se relaciona al propio proceso de maduración e incluye la necesidad de triunfo personal-, más que de negociación.

Asimismo, cabe resaltar que lo que hace que lo agresivo del crecimiento no termine en un "cadáver" es que el adolescente se siga sintiendo irresponsable e inmaduro tanto como el adulto debe ser maduro, lo que permite mantener entre ambos una especie de balance entre madurez e inmadurez: "donde existe el desafío de un joven en crecimiento, que haya un adulto para encararlo. $Y$ no es obligatorio que ello resulte agradable. En la fantasía inconsciente, estas son cuestiones de vida o muerte" (Winnicott, 1972, p.193).

Se puede entender entonces que si el adulto se confronta al adolescente como adulto, le hace sentir la cualidad emocional de que su agresividad no mata realmente, facilitándole el que pueda seguir utilizando su agresividad a nivel de la fantasía. En cambio, si confronta al adolescente como adolescente- esa confrontación ya no existe porque el adulto siente que el adolescente realmente lo puede matar, ya que le sería "reconocible" especularmente lo que el adolescente le muestra.

Permanece pues la idea fundamental de la gran riqueza de preservar la inmadurez. Hay que vivenciar suficiente inmadurez - través de la confrontación -, para luego ser suficientemente maduro. Esta preservación del par madurezinmadurez se podría tomar como una manifestación de lo que Winnicott desarrolla como integración psicosomática a través de la elaboración imaginativa de las funciones corporales:

O que faz a diferença entre o animal
humano e o resto dos animais não é a
instintualidade, mas a necessidade de operar
a 'elaboração imaginativa de todas as
funções corpóreas'... O homem não é
'movido' - empurrado a tergo - por tais
forças, ele acontece porque tem-que-
acontecer, porque, por essência, é
acontecencial, sendo essa acontecência
estruturada, na origem, por um trabalho da
psique sobre o corpo... a psique está no
bebê, num certo sentido e grau, desde o
início da vida. Ela não é uma substância ou
uma instância, e sim um modo de operar
da natureza humana... A identificação entre
a psique e a elaboração imaginativa do
corpo é feita já em 1949, quando Winnicott
diz que 'psique' significa 'a elaboração
imaginativa das partes somáticas, dos
sentimentos e das funções, isto é, do estar-
vivo fisicamente [physical aliveness]' 'Numa
outra formulação, lê-se que a psique' 'surge
como uma organização da elaboração
imaginativa do funcionamento corpóreo'
(Loparic, 20oo, p.359).

La confrontación participa de la integración psicosomática, pero también de cómo resolver el que crecer no es solamente ocupar un espacio personal, sino además el lugar de padre (o de un adulto) (Winnicott, 1972). En tal sentido, y aunque hay autores que presentan a Winnicott como un endogenista convencido (Bleichmar, 1997), la rebelión adolescente se podría ubicar no desde un "afuera", ni desde un "adentro", sino de un 
"entre" que remite al espacio transicional. Una hipótesis posible es que quizás la confrontación adolescente se configure como un espacio transicional específico de la adolescencia.

Por todo lo anterior, el fracaso en la confrontación acarrea que (Winnicott, 1972):

- La búsqueda de muerte recae sobre uno mismo como suicidio o ejerciendo la figura de dictador que espera la muerte de los hermanos, a los que se domina (lo que se podría hacer extensible al grupo de pares).

- El adolescente es un adulto en forma prematura (con consolidación del falso self).

- Ya no existe lucha por la responsabilidad. La misma es entregada o administrada por adultos.

- Los adultos se muestran comprensivos y alaban la inmadurez adolescente, lo que es el desastre de renunciar a la lucha y probablemente a la agresividad.

- Hay un acceso a identificaciones prematuras, a las cuales teme Winnicott, ya que incitan a la genitalidad y a la elección de objeto. Señala que la bisexualidad no se soluciona por elección de objeto heterosexual y que las relaciones sexuales no implican madurez sexual, porque la misma debe abarcar toda la fantasía inconsciente del sexo.

Por tanto, el objeto, el otro, instaura quizás prematuramente la diferencia de objetos y obtura la posibilidad de aceptarse a sí mismo.

\section{Educacion e inmadurez}

En este especial hincapié de la inmadurez adolescente, en la que se debe verificar un pasaje gradual hacia la madurez, el logro de la gradualidad es especialmente vital, gradualidad que no debe apresurarse ni enlentecerse. Para Winnicott, la gran o única cura para la adolescencia es probablemente - el paso del tiempo. Aunque ambos polos (madurez e inmadurez) operan como punto de llegada y de partida, no parece sin embargo que se articulen de forma simétrica ni equivalente. Podría decirse que

174 es desde la inmadurez que se ubica la posibilidad del self verdadero, al colocarla como espacio de generación de elementos creativos y transicionalescomo expresión de crecimiento. En definitiva, es esta inmadurez preservada la que permite la consolidación de la adolescencia como elemento "sagrado".

Por otro lado, las definiciones disponibles de madurez son: (1) pérdida no demasiado grande de espontaneidad personal, (2) imposición de lealtad a una zona de la realidad (como forma de lo sano), (3) sentirse (sin serlo realmente) libre e independiente, por lo que cabe pensar si no es una forma de falso self (Winnicott, 1972; 1981). Se puede notar que este sentido de la madurez no tiene nada que ver con la adaptación ni con la responsabilidad. En tal sentido, Winnicott es un escéptico de la adaptación a las normas sociales. A lo sumo, podría suponerse que la madurez es un simulacro de adaptación, un hacer "como si" hubiera madurez. Es una distinción fundamental, porque, a diferencia de otros autores, para Winnicott lo que el adolescente debe hacer fundamentalmente es crecer de forma gradual: "Sólo con el paso del tiempo y de la experiencia puede un joven aceptar poco a poco la responsabilidad por todo lo que ocurre en el mundo de la fantasía personal" (Winnicott, 1972, p.190).

El logro del crecimiento, es la tarea fundamental del adolescente. $Y$ a eso se une el sentido esencial de experiencia (Fulgencio, 2011). Por eso no hay nada que comprender ni dirigir, y ésa es la crítica radical de Winnicott a la educación. El adolescente no necesita a la educación para crecer, sino un ambiente suficientemente bueno. Por eso, desde la perspectiva winnicottiana, el concepto de una crianza y educación moderna, adecuada y racional es un problema porque implica un direccionamiento de las cosas. Y el crecimiento, insiste Winnicott, no se puede dirigir; en su lugar se debe destacar lo impredecible, lo gradual y lo sorprendente.

El ambiente facilitador, suficientemente bueno, es aquél que permite establecer una continuidad que anula lo predecible, tanto como evita lo perfecto. Porque el crecimiento, para ser tal realmente, ha de ser impredecible (es decir: no 
seguir un patrón ya programado) tanto como imperfecto (en el sentido de ser profundamente humano y no artificial). Crecimiento (suficientemente) bueno pasa a ser aquél en que el ser humano desarrolla toda su imperfección innata.

Por el contrario, la educación busca establecer un modelo homogeneizador de acuerdo a pautas estatales y sociales (Klein, 2006b), y esta homogeneización requiere aspectos de control. Hasta cierto punto: un "plan" artificial tratando de prevalecer sobre el "plan" natural del crecimiento. Sin embargo, cabe pensar si la crítica de Winnicott abarca toda la educación o aquella que justamente, por su carácter extremadamente planificado, no puede tener en cuenta o incluir el crecimiento adolescente. Diferentes experiencias parecen indicar que los adolescentes necesitan una educación que incluya educadores capaces de sostener la confrontación y sobrevivir a la agresividad de los mismos (Klein, 2006b).

¿A qué obedece este equívoco? Quizás esta dificultad obedece a la complejidad de cómo Winnicott conceptualiza la educación. Y al hecho de que hay algo en la educación que es intrínseco a la adolescencia (Klein, 2006a), (Ariés \& Duby, 1990). Sin duda, la perspectiva de Winnicott permite una vigorosa crítica al positivismo de la modernidad, en la cual la educación se ha hecho consubstancial a los derechos del individuo. Para la modernidad, el derecho primero - o uno de los principales -, del individuo es ser educado. Por el contrario, para Winnicott el derecho insalvable del individuo es crecer. En definitiva - y de forma más general -, esa idea tecnocrática de que las cosas se deben dirigir para que estén bien hechas es perjudicial.

Pero hay un punto más álgido en disputa. La educación, como proyecto de buena fe, requiere y necesita el agradecimiento, de seres agradecidos que le confirmen la necesidad de su existencia. Sin embargo - señala Winnicott (1972) -, el adolescente es básicamente un desagradecido. Winnicott constata una reacción interesante y que a los educadores les genera perplejidad: en vez de agradecimiento, la educación genera agresividad. Probablemente porque entre la educación y el crecimiento, este último tiene mejores chances de sobrevivir y esa agresividad que surge, si la tomamos como empuje de crecimiento, es la prueba palpable en tal sentido. Y como ya se indicó, la agresividad en la adolescencia, toma la forma de asesinato (simbólico). Ese es quizás otros de los motivos que impiden hacer coincidir la educación positivista con la adolescencia, porque no hay educación de este tipo (hay que destacar que Winnicott habla de educación en general, sin distinguir contextos, épocas o tipos de educación) que prevea o tolere el asesinato (simbólico o lúdico) del padre.

Por lo tanto, la educación enfocada desde el positivismo parece ser el negativo del crecimiento y del ambiente facilitador, oponiéndose a ellos: cuanto más el proyecto político de ciudadanía se acerca a un ideal de perfección, más se opone al crecimiento. Está claro que ningún educador admitiría tales ribetes, pero es posible recordar que la figura más inquietante de la pedagogía, dentro de la contemporaneidad, es la del padre de Schreber, el Gran Pedagogo (Freud, 1911), ejemplo siniestro de las consecuencias de la radicalidad del programa educativo modernista.

Por otra parte, según Ariès y Duby (1990), y de acuerdo al estudio del origen de las subjetividades, es la institución educativa la que genera - junto a otros factores - adolescencia en la modernidad (Klein, 2006a). Así lo quiera o no Winnicott, y aunque sus críticas son compartibles, algo de la educación retorna, algo inevitablemente retornará, si discutimos sobre adolescencia. Es algo implícito en Winnicott este papel cofundador de la educación en la adolescencia, ya que señala que su rebelión se da por la propia libertad ofrecida por la educación.

A pesar de eso cabe destacar que, al mismo tiempo y contradictoriamente, el autor señala que la necesidad de triunfo personal surge por el propio proceso de maduración. Vale decir, la rebelión pasó del tablero de la educación al del crecimiento. Este es un escollo epistemológico en el análisis de Winnicott, que se pueda enfocar, al mismo tiempo, como una paradoja que enriquece el debate entre educación y crecimiento

Hagamos ahora una pregunta esclarecedora. En el pasaje de la educación al crecimiento, ¿quién 
se opone a esa figura siniestra, la del Gran Pedagogo? A mi entender, a la figura del Gran Pedagogo se opone la del adulto confrontante. Winnicott parece indicar que lo que un adolescente necesita de los adultos, es que los mismos sobrevivan- pero no que los eduquen. Porque adulto es el que sobrevive a la confrontación, no el que educa. El adulto no debe abdicar, debe sobrevivir. ¿A qué? A la agresividad adolescente. Pero aún así, quizás se debería ser más cuidadoso. Porque un adolescente puede necesitar a sus padres en calidad de adultos y de capacidad de supervivencia, y necesitar también la capacidad de educación de otros adultos que no sean sus padres, siempre y cuando, como ya se indicó, sea una educación que contenga y tolere la capacidad de crecimiento y espontaneidad del joven.

\section{El lugar reservado a la agresividad}

Volvamos nuevamente a la temática de la agresividad. Como ya indicamos, la agresividad en Winnicott es indisociable de la idea de crecimiento, de una fuerza que hace a la maduración y la continuidad del self. Podría pensarse que existe una línea de desarrollo del ser y una línea de desarrollo instintivo que es necesario diferenciar. El cuerpo vivo, que se podría tomar como desarrollo del ser, tiene como tal una organización y una temporalidad previas a la elaboración imaginativa (Loparic, 2000). En relación al mismo, Winnicott menciona "tensiones instintivas", impulsos biológicos que no tienen aún formato instintivo, a los que diferencia de los propios instintos como forma de elaboración - línea de desarrollo instintivo - cargados de fuerza y "que exigen acción" (Winnicott, 1979):

Em decorrência da tendência ao crescimento (é precisamente aqui que se mostra a temporalidade sui generis do corpo), surgem novas maneiras de funcionamento e novos tipos de organização dos tecidos, dos órgãos e do cérebro que possibilitam novos modos de vida, por exemplo, aqueles que permitem o surgimento da agressividade enquanto tal, 176 das paixões, da fala e da consciência. Devido ao fato de estar vivo e de crescer, e não apenas em virtude de ser um aparelho físicoquímico, o corpo humano guarda para o indivíduo um caráter de opacidade, o que faz com que o alojamento da psique no corpo seja sempre precário e ameaçado, permanecendo uma tarefa que só termina com a morte (Loparic, 2000, p.364)

¿Cuáles son por otra parte las relaciones entre violencia y vida libidinal? Winnicott (1984) indica cómo el bebé aniquila el mundo ya desde una etapa temprana, con solo cerrar los ojos, y cómo puede recrearlo con su mirada, de acuerdo a formas de magia infantil. Winnicott entiende que esta destrucción se verifica en cuanto los objetos pasan de ser "parte" de él a ser algo "distinto" a él. La violencia es inseparable entonces de la posibilidad de preservar el sentido de continuidad y de crecimiento del mundo interno frente a aquello que se puede volver "extraño" o "irreconocible". Podría pensarse que, en la medida que se destruye violentamente al objeto, se preserva libidinalmente el ser, lo que se aplica a la situación del adolescente:

La violencia en este caso está al servicio del desarrollo de un espacio psíquico propio, secreto. Se trata en primer lugar y particularmente en la adolescencia, de todo aquello que toca a la sexualidad, regida en todas las sociedades por las prohibiciones que se relacionan con la vida sexual y su intimidad. El secreto garantiza la autonomía psíquica y afirma la libertad personal, por lo que debería preservarse ese espacio íntimo e inviolable para comenzar a crear esa zona de intimidad, generadora de la propia subjetividad (Flechner, 2003, p.172)

Esta concepción de una violencia estructurante que surge como forma de preservar y ocupar un espacio personal, como forma de encuentro del self, está presente asimismo en Winnicott:

Si se hace todo lo posible para promover el crecimiento personal de los descendientes, habrá que hacer frente a resultados sorprendentes. Si sus hijos llegan a encontrarse a sí mismos, no se conformarán 
con encontrar algo, sino que buscarán la totalidad, y ello incluirá la agresión y los elementos destructivos que existen en ellos. (Winnicott, 1972, p.185).

\section{Conclusión}

Como ya se indicó el modelo que Winnicott desarrolla sobre la adolescencia es sumamente original y se diferencia de otras propuestas psicoanalíticas En este trabajo se ha intentado desarrollar algunas de sus varias contribuciones..

Uno de los puntos que cabria destacar es que, hasta cierto punto, el modelo de adolescencia de Winnicott pasa a depender considerablemente de la actitud del adulto, lo que relativiza nuevamente el supuesto edogenismo de Winnicott. Se podría sugerir que si la adolescencia necesita adultos que sean adultos y no actúen como adolescentes, es porque sólo como adultos percibirán una fantasía en la agresividad del crecimiento. Si no actúan en carácter de adultos, si estuvieran adolescentizados, percibirán de la agresividad no la fantasía, sino el acto, y reaccionarán como si éste fuera equivalente a lo real.

Quedarían en posición de igual a igual con el adolescente, especularizados con él. Si el adulto confronta al adolescente como adolescente; ya no hay confrontación, porque siente que el adolescente realmente puede asesinarlo, porque lo que el otro le muestra le es "reconocible", en cuanto adolescentizado. Termina el juego - el "como si" y lo lúdico y comienza la amenaza, lo ominoso, el drama hórdico... Pero en el mejor de los casos - y aquí podríamos ofrecer otra caracterización de confrontación -, la confrontación opera como un diferenciador entre Adultos y Adolescentes.

Existe otro punto importante a destacar. $\mathrm{Si}$ la adolescencia y la confrontación están íntimamente entrelazadas, podemos revisar la opinión por la cual cuando Freud trataba sus primeras histéricas (por ejemplo Anna O.), trataba en realidad adolescentes. El mismo Freud, hay que destacarlo, realiza un parangón entre histeria y adolescencia. Pero desde las ideas aquí desarrolladas esta semejanza se invalida.
Freud trataba histéricas y no adolescentes. O mejor dicho: trataba histéricas que no habían podido desarrollar adolescencia. Más aún: cabe pensar que la histeria es un mecanismo contrario a la adolescencia. Es un proceso de anti-adolescencia. Revisando los historiales freudianos (Freud, 1895) se puede observar que a estas histéricas les era imposible confrontar a sus padres. Padres moribundos, débiles, exhaustos, enfermos o muertos, que no cumplían con los requisitos estructurales para llevar adelante, para sostener y/ o garantizar la confrontación generacional.

Finalmente una especial dificultad, que ya se indicó previamente, es que el sistema conceptual winnicottiano requiere adolescentes y adultos diferentes y bien demarcados entre sí, con cierta idealización de ambos en sus rasgos y características. Pero cabe preguntarse: ¿qué sucede cuando el adolescente ya no sostiene inmadurez e irresponsabilidad? ¿O cuando el adulto ya no puede sostener su adultez desde condiciones sociales y culturales, que modifican el sentido y la función de lo adulto en la sociedad?

Sin poder desarrollarlo aquí, quizás sea pertinente indicar que las condiciones estructurales de la confrontación con las figuras parentales, desde este contexto, se modifican profundamente, surgiendo en el adolescente actitudes de culpa y remordimiento por esa agresividad, las cuales ya no pueden ser transformadas en factor de crecimiento. Por otro lado, parecen surgir en el adolescente, actitudes de responsabilidad y sobreresponsabilidad (algo sobre lo que justamente Winnicott alerta en sus reflexiones) que se podrían ubicar como mesiánicas, dando lugar inclusive a situaciones de "mesianismo exacerbado" donde la espontaneidad winnicottiana se substituye por una actitud de cuidado y protección de su entorno familiar.

\section{Referencias}

Ariès, P., \& Duby, G. (Orgs.). (1990). La comunidad, el estado y la familia. In Historia de la vida privada (Tomo VI). Buenos Aires: Taurus. 
Bleichmar, H. (1997). Avances en psicoterapia psicoanalítica: hacia una técnica de intervenciones especificas. Madrid: Paidós.

Bleichmar, N., \& Bleichmar, C. (1999). El psicoanálisis después de Freud: teoría y clínica. Ciudad de México: Paidós Ibérica.

Dolto, F. (1990). La causa de los adolescentes. Madrid: Seix Barral.

Dör, J. (1990). El padre y su función en psicoanálisis. Buenos Aires: Ed. Nueva Visión.

Erikson, E. (1991). Sociedad y adolescencia. Ciudad de México: Siglo XXI.

Erikson, E. (2009). Infancia y sociedad. Buenos Aires: Paidós.

Flechner, S. (2003). De agresividad y violencia en la adolescencia. Revista Uruguaya de Psicoanálisis, 98, 163-183.

Freud, S. (1895). Escritos sobre la histeria (Tomo II). Buenos Aires: Amorrortu.

Freud, S. (1905). Tres ensayos de teoría sexual (Tomo VII). Buenos Aires: Amorrortu.

Freud, S. (1911). Sobre un caso de paranoia descrito autobiográficamente y otras obras (Tomo XII). Buenos Aires: Amorrortu.

Freud, S. (1913). Tótem y tabú (Tomo XIII). Buenos Aires: Amorrortu.

Freud, A. (1985). Psicoanálisis del desarrollo del niño y el adolescente. Buenos Aires: Paidós.

Fulgencio, L. (2011). A importância da noção de experiência no pensamento de D. W. Winnicott. Estudos de Psicologia (Campinas), 28(1), 57-64. doi: 10.1590/ S0103-166X2011000100006

Kancyper, L. (1992). Resentimiento y remordimiento: estudio psicoanalítico. Buenos Aires: Paidós.

Klein, A. (2002). Imágenes del adolescente desde el psicoanálisis y el imaginario social: condiciones de surgimiento de la adolescencia desde la modernidad y el disciplinamiento adolescentizante desde la posmodernidad. Montevideo: Psicolibros.

Klein, A. (2003). Escritos psicoanalíticos sobre psicoterapia, adolescencia y grupo. Montevideo: Psicolibros.

Klein, A. (2004). Adolescencia, un puzzle sin modelo para armar. Montevideo: Psicolibro - Waslala.

Klein, A. (2006a). Adolescentes sin adolescencia: reflexiones en torno a la construcción de subjetividad adolescente bajo el contexto neoliberal. Uruguay: Psicolibro Universitario.

Klein, A. (2006b). El estudio y lo institucional metonímico en la adolescencia: el neoliberalismo es hacer de suplentes. Psicologia em Revista, 12(20), 181-192

Kohut, H. (1977). Análisis del Self: el trastorno psicoanalítico de los trastornos narcisistas de la personalidad. Buenos Aires: Amorrortu.

Laplanche, J., \& Pontalis, J.-B. (1981). Diccionario de psicoanálisis. Barcelona: Labor.

Loparic, Z. (2000). O "animal humano". Natureza Humana, 2(2), 351-397. Recuperado em maio 21, 2012 , de http://pepsic.bvsalud.org/scielo

Maier, H. (1980). Tres teorías sobre el desarrollo del niño. Buenos Aires: Amorrortu.

Winnicott, D. (1972). Realidad y juego. Barcelona: Gedisa.

Winnicott, D. (1979). Escritos de pediatría y psicoanálisis. Barcelona: Laia.

Winnicott, D. (1981). El proceso de maduración en el niño. Barcelona: Laia.

Winnicott, D. (1984). Deprivación y delincuencia. Buenos Aires: Paidós.

Winnicott, D. (1994). Conozca a su niño: psicología de las primeras relaciones entre el niño y su familia. Barcelona: Paidós.

Recibido el: 30/5/2012

Versión final el: 5/11/2012

Aprobado el: 22/11/2012 